\title{
A PROSPECTIVE EVALUATION OF CAUSES AND TREATMENT OF INFERTILITY IN A TERTIARY CARE HOSPITAL, ERODE
}

\author{
AMALA BABY ${ }^{1}$, ANILA A VARGHESE ${ }^{1}$, CINDY JOSE ${ }^{1}$, KRISHNAVENI KANDASAMY ${ }^{1}$, SHANMUGA SUNDARAM \\ RAJAGOPAL ${ }^{2 *}$
}

${ }^{1}$ Department of Pharmacy Practice, J.K.K Nattraja College of Pharmacy, Kumarapalayam - 638 183, Namakkal, Tamil Nadu, India. ${ }^{2}$ Department of Pharmacology, J.K.K Nattraja College of Pharmacy, Kumarapalayam - 638 183, Namakkal, Tamil Nadu, India. Email: malshan34@gmail.com

Received: 19 August 2017, Revised and Accepted: 01 November 2017

\section{ABSTRACT}

Objective: Infertility has a serious impact on the psychosocial well-being of women in the developing world. The objective of the study was to evaluate the causes and treatment pattern of infertility patients in a tertiary care hospital.

Methods: The prospective observational study focused on the sociodemographic properties of infertile patients, causes of infertility, and various treatments carried out in a tertiary care hospital, Erode, Tamil Nadu.

Results: Of 200 cases, the majority was due to female factor (45.5\%), followed by male factors (26\%), both gender factors (25.5\%), and unexplained etiology (6\%). It was observed that major causes of male infertility (MI) were oligoasthenoteratozoospermia (OATS - 48.42\%), followed by asthenozoospermia (17.89\%), azoospermia (11.57\%), erectile dysfunction (7.36\%), oligoasthenozoospermia (5.26\%), varicocele (3.15\%), oligospermia (2.10\%), necrozoospermia (2.10\%), asthenoteratozoospermia (1.05\%), and asthenozoospermia+erectile dysfunction (1.05\%). In cases of female infertility (FI), the pattern of causes was polycystic ovarian disease (PCOD) (29.6\%), followed by tubular block (13.23\%), cyst (6.66\%), hypothyroidism (4.44\%), endometriosis (4.44\%), hormonal problems (4.44\%), fibroid (3.7\%), fibroid+cyst (3.7\%), premature ovarian failure (2.96\%), thin endometrium (2.96\%), multifollicularovary (2.96\%), PCOD+hormonalproblems (2.96\%), and hypothyroidism+hormonal problems (2.22\%). Intrauterine insemination was the most commonly assisted reproductive technology employed, followed by in vitro fertilization and intracytoplasmic sperm injection. Of 200 infertile couples, 57 (28.5\%) were unable to conceive within 6 months and 72 (36\%) after 6 months following first consultation, $44(22 \%)$ defaulted/lost follow-up/were still under consultation, $13(6.5 \%)$ conceived with the help of assisted reproductive treatment, 10 (5\%) conceived with the help of drug treatment, anddd $4(2 \%)$ had spontaneous pregnancy.

Conclusion: The major cause of infertility was found to be PCOD in females and OATS in males. The most commonly prescribed drugs were antioxidants for males and progesterone for females.

Keywords: Infertility, Polycystic ovarian disease, Oligoasthenoteratozoospermia.

(C) 2018 The Authors. Published by Innovare Academic Sciences Pvt Ltd. This is an open access article under the CC BY license (http://creativecommons. org/licenses/by/4. 0/) DOI: http://dx.doi.org/10.22159/ajpcr.2018.v11i2.22108

\section{INTRODUCTION}

Infertility being a worldwide health issue affects about $8-10 \%$ couples globally [1,2]. According to the World Health Organization (WHO), it was estimated that 60-80 million couples all over the world currently suffer from infertility [3]. Infertility is not only an issue of physical wellbeing but also a matter of social discrimination and disparity. Infertility can have a grave impact on both the psychological and the social welfare of women in the developing world, as they grieve physical and mental abuse, neglect, desertion, economic deprivation, and social isolation as well as prohibition from certain social activities and traditional ceremonies [4].

The WHO defines primary infertility as the "inability to conceive within 2 years of exposure to pregnancy" (i.e., sexually active, non-contracepting, and non-lactating) among women 15-49 years old. Secondary infertility refers to the inability to conceive following a previous pregnancy. Globally, primary infertility is more predominant [5].

Diagnostic assessment of infertility is done when pregnancy has not been achieved within 1 year of regular noncontraceptive intercourse, by which time $85-90 \%$ of couples attempting conception should be successful [6]. Since infertility is not a life-threatening condition, it has not given a due attention in India.
Infertility has an extensive range of reasons stemming from three general sources: Physiological dysfunctions, preventable causes, and unexplained matters. The biological and social factors such as stress due to financial status, religious beliefs, age at marriage, higher literacy, contraceptive usage, and nuclear families play a important part in lowering fertility [7]. Sexually transmitted infections are one of the chief preventable causes of infertility worldwide, especially in developing countries [8]. Anatomical, genetic, hormonal, and immunological problems also contribute to infertility [9]. Physiological causes of female infertility (FI) include: Ovulatory dysfunction, congenital malformation, tubal blockage, and endometriosis. The etiology of infertility in males is less understood, though the causes of infertility are anatomic flaws, ejaculatory failures, endocrinopathies, chemotherapy, immunologic problems, gene mutation, radiation, and environmental threats [10].

After a thorough evaluation, the majority of the infertile couples does receive a firm diagnosis. The management of infertility extends from the use of drugs to use of techniques like in vitro fertilization (IVF).

\section{Treatment for male infertility (MI)}

Dopamine agonists can be beneficial in patients with hyperprolactinemia [11]. Erectile dysfunction should be treated if indicated [12]. If block or a varicocele is diagnosed to be concomitant 
with seminal fluid abnormalities, surgical treatment can be pursued. Injection gonadotropin, intrauterine insemination (IUI), and IVF with or without sperm injection, using testicular sperm extraction, can be the options for management, based on the causes [13]

\section{Treatment for FI}

Underlying etiology of abnormal ovulation, such as thyroid dysfunction, should be corrected.

Insulin-sensitizing agents, metformin can increase ovulation and conception rates in patients with polycystic ovary syndrome (PCOS) [14]. If the drug treatment failed, laparoscopic ovarian drilling can be another choice for patients with PCOS. Tubal reparative surgery can be the treatment option for tubal disease [15]. IVF is an alternative choice, mainly in case of distinctly damaged tubes [16]. Laparoscopic ablation or laparotomy can be used in treating endometriosis, based on the condition of the disease. Treatment strategies for unexplained infertility are clomiphene citrate, IUI, and IUI with clomiphene citrate or gonadotropin therapy.

\section{METHODS}

This prospective study was performed in a tertiary care hospital in Erode, within a period of 6 months, in 200 infertile couples who were undergoing treatment. The study included males of age above 18 years of age and females aged between 18 and 49 years, patients with comorbidities, and the study excluded surrogate women, postmenopausal women, non-adherence of treatment, and unmarried women seeking child.

\section{RESULTS}

Among 200 infertility cases collected, 26\% were male factor, 45.5\% female factor, $25.5 \%$ due to both gender factors, and $6 \%$ with unexplained factor. It was observed that 76 (51.35\%) females were in the age group of $20-29$ years and $76(69.72 \%)$ males in the age group of 30-39 years. 181 (90.5\%) were primary infertility, and 19 (9.5\%) were secondary infertility. It was found that $53.5 \%$ of the couples suffered from infertility for $<5$ years. It was observed that $38.52 \%$ of the males and $51.31 \%$ of the females are of blood group 0 . It is found that
$64.86 \%$ of males and $68.80 \%$ of the females belonged to normal body mass index (BMI) (18.5-25). 61.496\% of infertile men were smokers, and $38.53 \%$ were non-smokers. $39 \%$ of males and $34 \%$ of the females had high school education, and all males and $89.5 \%$ of the females were employed. It was observed that the most common comorbid disease found in FI was polycystic ovarian syndrome $(24.5 \%)$. It was followed by menstrual problems (24\%), hypothyroidism (7.5\%), fibroid $(4 \%)$, diabetes mellitus $(3.5 \%)$, endometriosis $(3 \%)$, uterine polyps $(1.5 \%)$, adenomyosis $(1.5 \%)$, UTI $(0.5 \%)$, appendicitis $(0.5 \%)$, and tuberculosis $(0.5 \%)$. The comorbid disease found in MI was found to be varicocele $(6 \%)$ and hernia $(0.5 \%)$, and then, $19.5 \%$ of patients were without any comorbidities. $51.5 \%$ of couples had positive toward assisted reproductive treatment (ART) and $48.5 \%$ of the couples had a negative attitude toward ART. IUI (36.5\%) was found to be the most commonly used assisted reproductive technology. The findings on the causes of male and FI are shown in Figs. 1 and 2, respectively. Our study showed that the most prescribed drug for MI was antioxidants and for progesterone for FI (Tables 1 and 2). It was observed that, of 200 infertile couples, 72 (36\%) were unable to conceive after 6 months following the first consultation, 57 (28.5\%) were unable to conceive within 6 months following the first consultation, $44(22 \%)$ defaulted, lost follow -up, or were still under consultation, 13 (6.5\%) were pregnant with the help of ART, $10(5 \%)$ were pregnant with the help of drug treatment, and 4 (2\%) had spontaneous pregnancy.

\section{DISCUSSION}

In this study, the higher occurrence of female factor infertility could be due to the vital role played by females in the process of reproduction and the complex anatomical structure. Adamson et al., [8] in their study on the prevalence and correlates of primary infertility among young women in Mysore, India, found that the mean age of women with infertility was $25.9 \pm 3.12$ year. The semen analysis reports in the study performed by Samal et al. [17] revealed that those in the age group of 31-40 years were mostly affected. Although patient's age is said to affect their fertility, our study does not establish a definite relationship in patient's age and infertility, as most of the couples fit into the reproductive age group which does not expressively affect their fertility. The higher incidence of primary infertility observed in our

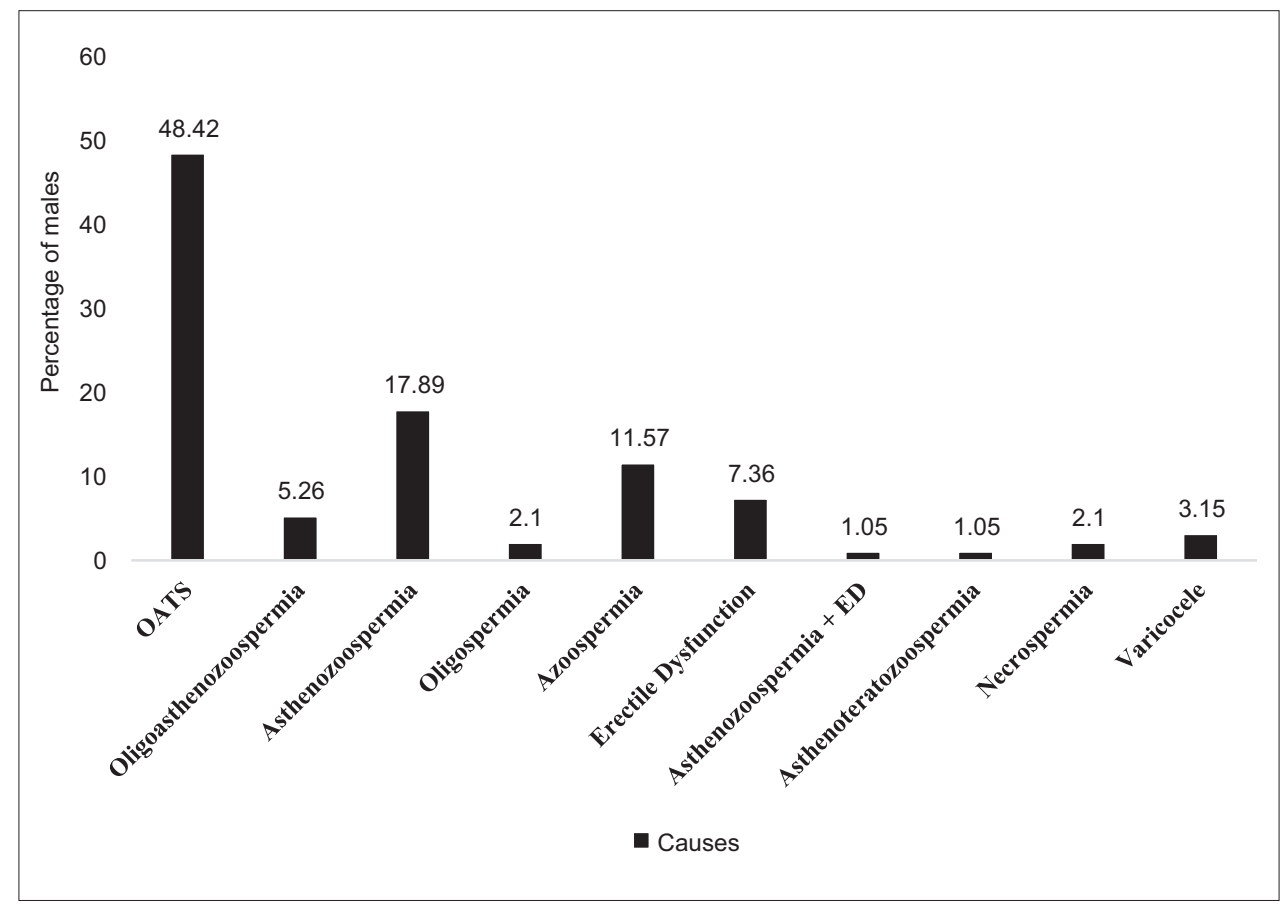

Figure 1: Causes of infertility in male 


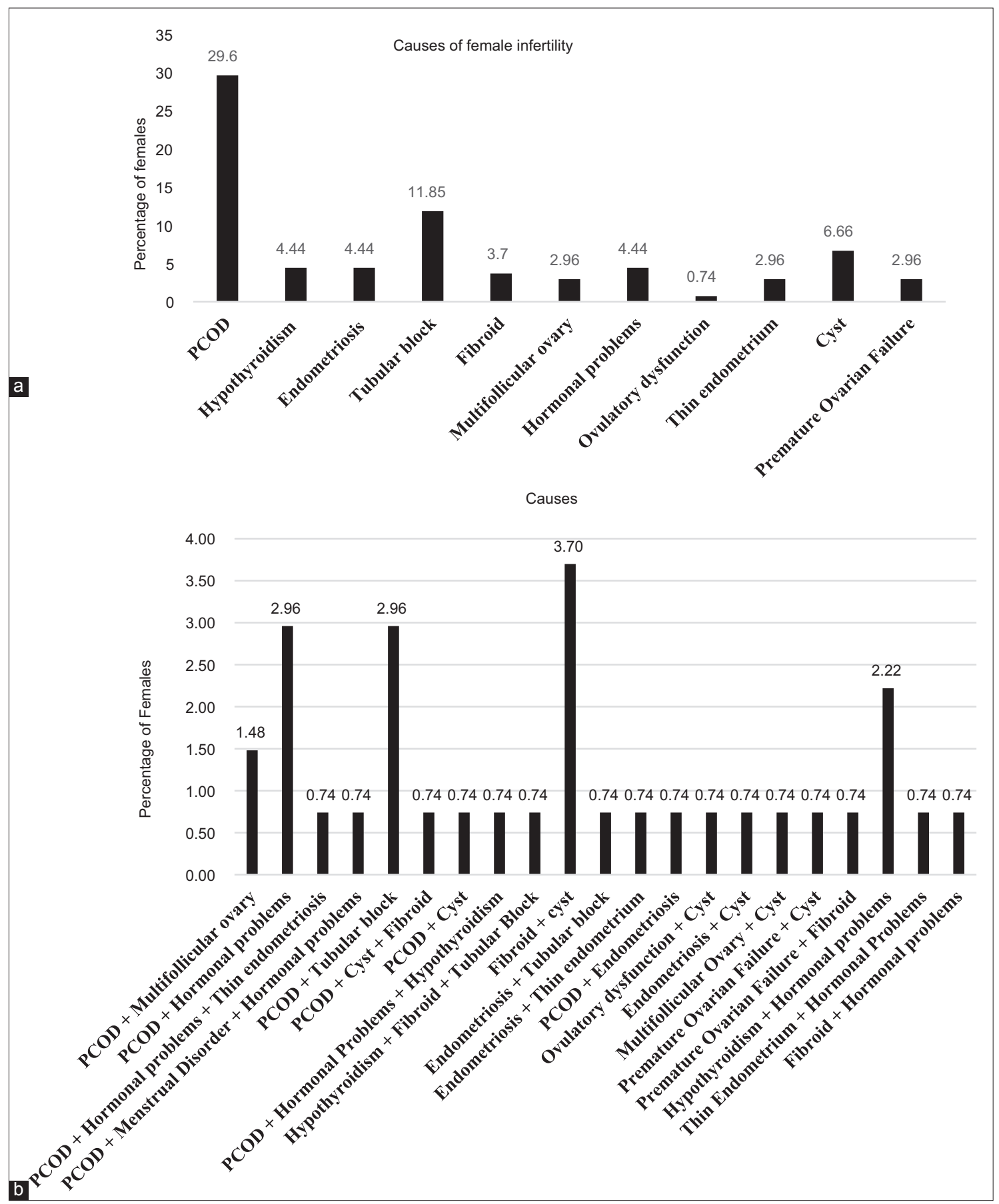

Fig. 2: (a) Causes of female infertility, (b) causes of female infertility

study is comparable with the study on the prevalence and correlates of primary infertility among young women in Mysore, India, conducted by Paul et al. [8]. Higher the extent of infertility, lesser number was found to approach the health-care facility for treatment seeking. This might be due to the influence of sociocultural factors in different regions of the country as well as the fact that couples present first to general practitioners before seeking specialist care and also wait passively or seek unorthodox care. Khan et al. [18] found that most of the infertile men belonged to blood group 0 (35.5\%), and Huda [19] found that most of the infertile females belonged to the blood group 0 (41.6\%). This finding can be accredited to the element that women with blood group $\mathrm{O}$ have a lesser ovarian reserve and follicle-stimulating hormone (FSH) count above 10, which is indicative of infertility. A study conducted by Shanthakumari et al. [20] stated that the BMI showed a few women
$(10 \%)$ were underweight, some women $(8.3 \%)$ were obese, and most of the women $(26.7 \%)$ had overweight, whereas women $(55 \%)$ had normal body weight. This might be due to the fact that the estrogen produced by the fat cells, along with that naturally synthesized in the body, is misinterpreted by the body as a birth control signal, which results in failure to achieve pregnancy. Total sperm count was found to be inversely related to BMI in crude analyses. BMI was also linked to sex hormone-binding globulin, lower serum levels of total testosterone and inhibin B, and higher serum levels of estradiol. In addition, FSH levels and the testosterone:luteinizing hormone $(\mathrm{LH})$ ratio were considerably lower among obese men (BMI R35 kg/m²) [21]. Effects of smoking, a lifestyle hazard for both active and passive smokers, on fertility status have been less documented. The sperm abnormality is caused by the potential hazardous chemicals present in cigarette smoke which 
Table 1: Treatment for males

\begin{tabular}{|c|c|c|}
\hline $\begin{array}{l}\text { Male factors of } \\
\text { infertility }\end{array}$ & Treatment & $\begin{array}{l}\text { Number of } \\
\text { patients } \\
\text { receiving } \\
\text { treatment }(\%)\end{array}$ \\
\hline \multirow{7}{*}{$\begin{array}{l}\text { OATS } \\
(n=46)\end{array}$} & Progesterone & $29(63.0)$ \\
\hline & Vitamins & $31(67.3)$ \\
\hline & Antioxidants & $11(23.9)$ \\
\hline & Hormonal treatment & $28(60.8)$ \\
\hline & Gonadotropin & 05 (10.8) \\
\hline & Antibiotics & $05(10.8)$ \\
\hline & Dopamine agonists & $01(2.2)$ \\
\hline \multirow{7}{*}{$\begin{array}{l}\text { Asthenozoospermia } \\
(n=18)\end{array}$} & Dopamine agonist & $03(16.6)$ \\
\hline & Antioxidants & $09(50)$ \\
\hline & Hormonal therapy & $18(100)$ \\
\hline & Progesterone & $16(88.8)$ \\
\hline & Antibiotics & $10(55.5)$ \\
\hline & Vitamins & $18(100)$ \\
\hline & Gonadotropin & 05 (27.7) \\
\hline \multirow{8}{*}{$\begin{array}{l}\text { Oligospermia } \\
(\mathrm{n}=2) \\
\text { Erectile dysfunction } \\
(\mathrm{n}=8)\end{array}$} & Aromatase inhibitors & $02(100)$ \\
\hline & Vitamins & 07 (87.5) \\
\hline & Phosphodiesterase & \\
\hline & inhibitors & $01(12.5)$ \\
\hline & Progesterone & $07(87.5)$ \\
\hline & Antioxidants & $06(75)$ \\
\hline & Gonadotropin therapy & $07(87.5)$ \\
\hline & Hormonal treatment & $04(50)$ \\
\hline \multirow{5}{*}{$\begin{array}{l}\text { Oligoasthenozoospermia } \\
(n=5)\end{array}$} & Aromatase inhibitors & $02(40)$ \\
\hline & Hormonal therapy & $03(60)$ \\
\hline & Antioxidants & $04(80)$ \\
\hline & Vitamins & $03(60)$ \\
\hline & Progesterone & $03(60)$ \\
\hline \multirow{4}{*}{$\begin{array}{l}\text { Azoospermia } \\
(\mathrm{n}=11)\end{array}$} & Progesterone & $09(81.8)$ \\
\hline & Gonadotropin & $08(72.7)$ \\
\hline & Vitamin & $11(100)$ \\
\hline & Antibiotics & $02(18.1)$ \\
\hline \multirow[t]{2}{*}{$\begin{array}{l}\text { Varicocele } \\
(n=3)\end{array}$} & $\begin{array}{l}\text { Dopamine receptor } \\
\text { agonist }\end{array}$ & $01(33.3)$ \\
\hline & Varicocelotomy & $02(66.6)$ \\
\hline \multirow{4}{*}{$\begin{array}{l}\text { Necrozoospermia } \\
(n=2)\end{array}$} & Progesterone & $01(50)$ \\
\hline & Vitamins & $02(100)$ \\
\hline & Dopamine & $01(50)$ \\
\hline & Hormonal therapy & $02(100)$ \\
\hline $\begin{array}{l}\text { Asthenoteratozoospermia } \\
(\mathrm{n}=1)\end{array}$ & Antioxidants & $01(100)$ \\
\hline
\end{tabular}

affects the chromosomes. A similar observation was found by Nadeem et al. [13], in which $66.7 \%$ of smokers showed below $5 \%$ sperm motility and $74.1 \%$ showed below $3 \%$ normal sperm morphology. We did not see any significant relation between infertility and the educational status of the patients.

Most of the couples had a positive approach toward ART due to high education, socioeconomic factors. A similar observation was found by Olugbenga et al. [22] in which $76.8 \%$ of the couples had a positive attitude to ART. The reason behind the negative attitude toward ART could be lack of proper awareness regarding the assisted reproductive technologies, inability to afford the treatment expenses, and certain religious aspects. The precise reason for the reduction in semen quality is not well understood, but it might be due to environmental, nutritional, and socioeconomic or other unknown causes [23-25]. PCOS is the major cause of infertility, with a wide spectrum of symptoms and clinical and biological manifestations, menstrual irregularities, obesity, and hirsutism. Several factors such as sedentary lifestyle, family history, and hormonal imbalance actively cause PCOS. Numerous antioxidants nutrients such as coenzyme Q10, vitamin C, vitamin E, and glutathione
Table 2: Treatment regimen for female infertility

\begin{tabular}{|c|c|c|}
\hline $\begin{array}{l}\text { Female factors of } \\
\text { infertility }\end{array}$ & Treatment & $\begin{array}{l}\text { Number of } \\
\text { patients } \\
\text { receiving } \\
\text { treatment (\%) }\end{array}$ \\
\hline \multirow{7}{*}{$\begin{array}{l}\text { Hormonal problems } \\
(\mathrm{n}=24)\end{array}$} & Progesterone & $20(83.3)$ \\
\hline & Hormonal therapy & $14(58.3)$ \\
\hline & Aromatase inhibitor & $08(33.3)$ \\
\hline & Ovulation inducers & $14(58.3)$ \\
\hline & Vitamin supplements & $15(62.5)$ \\
\hline & Gonadotropin therapy & $09(37.5)$ \\
\hline & Dopamine agonist & $08(33.3)$ \\
\hline \multirow{6}{*}{$\begin{array}{l}\text { Tubular block } \\
(\mathrm{n}=19)\end{array}$} & Antioxidant & 03 (15.7) \\
\hline & Progesterone & $12(63.1)$ \\
\hline & Ovulation inducers & 03 (15.7) \\
\hline & Gonadotropin therapy & 07 (36.8) \\
\hline & Hormonal treatment & 15 (78.9) \\
\hline & Vitamins & $02(10.5)$ \\
\hline \multirow{9}{*}{$\begin{array}{l}\text { PCOD } \\
(n=57)\end{array}$} & Ovulation inducers & $10(16.9)$ \\
\hline & Progesterone & 39 (66.1) \\
\hline & Hormonal therapy & $39(66.1)$ \\
\hline & Vitamins & $45(76.2)$ \\
\hline & Antidiabetic drugs & $16(27.1)$ \\
\hline & Antioxidants & $03(5.0)$ \\
\hline & Ovarian drilling & $05(8.4)$ \\
\hline & Aromatase inhibitors & $19(32.2)$ \\
\hline & Gonadotropin therapy & $15(25.4)$ \\
\hline \multirow{6}{*}{$\begin{array}{l}\text { Fibroid } \\
(n=5)\end{array}$} & Myomectomy & $02(40)$ \\
\hline & Progesterone & $04(80)$ \\
\hline & Vitamins & $05(100)$ \\
\hline & Ovulation inducers & $02(40)$ \\
\hline & Hormonal therapy & $04(80)$ \\
\hline & Dopamine agonists & $01(20)$ \\
\hline \multirow{5}{*}{$\begin{array}{l}\text { Thyroid problems } \\
(\mathrm{n}=12)\end{array}$} & Progesterone & $03(27.2)$ \\
\hline & Antithyroid drugs & $07(63.6)$ \\
\hline & Hormonal therapy & $04(36.3)$ \\
\hline & Vitamins & $06(54.5)$ \\
\hline & Gonadotropin therapy & $02(18.1)$ \\
\hline \multirow{7}{*}{$\begin{array}{l}\text { Endometriosis } \\
(n=6)\end{array}$} & Progesterone & $09(90)$ \\
\hline & Vitamins & $07(70)$ \\
\hline & Hormonal therapy & $06(60)$ \\
\hline & Gonadotropin therapy & $02(20)$ \\
\hline & Aromatase inhibitor & $02(20)$ \\
\hline & Ovulation inducers & $05(50)$ \\
\hline & Dopamine agonist & $01(10)$ \\
\hline \multirow{3}{*}{$\begin{array}{l}\text { Ovulatory dysfunction } \\
(\mathrm{n}=1)\end{array}$} & Progesterone & $01(100)$ \\
\hline & Hormonal therapy & $01(100)$ \\
\hline & Aromatase inhibitors & $01(100)$ \\
\hline \multirow{6}{*}{$\begin{array}{l}\text { Thin Endometrium } \\
(\mathrm{n}=7)\end{array}$} & Progesterone & $02(28.5)$ \\
\hline & Hormonal therapy & $03(42.8)$ \\
\hline & Vitamins & $03(42.8)$ \\
\hline & Ovulation inducers & $02(28.5)$ \\
\hline & Gonadotropin & $02(28.5)$ \\
\hline & Progesterone & $05(71.4)$ \\
\hline Cyst & Progesterone & $10(83.3)$ \\
\hline \multirow[t]{4}{*}{$(n=12)$} & Hormonal therapy & $12(100)$ \\
\hline & Vitamins & $12(100)$ \\
\hline & Dopamine agonist & $01(8.3)$ \\
\hline & Gonadotropin therapy & $02(16.6)$ \\
\hline \multirow{5}{*}{$\begin{array}{l}\text { Premature ovarian } \\
\text { failure } \\
(n=3)\end{array}$} & Antioxidants & $01(33.3)$ \\
\hline & Vitamins & $01(33.33)$ \\
\hline & Progesterone & $02(66.66)$ \\
\hline & Hormonal therapy & $02(66.66)$ \\
\hline & Aromatase inhibitors & $03(100)$ \\
\hline \multirow{4}{*}{$\begin{array}{l}\text { Unexplained factors } \\
(\mathrm{n}=12)\end{array}$} & Progesterone & $10(83.3)$ \\
\hline & Vitamins & $10(83.3)$ \\
\hline & Hormonal therapy & $04(33.3)$ \\
\hline & Ovulation inducers & $04(33.3)$ \\
\hline
\end{tabular}


have been acknowledged in several studies as having modulatory effects on sperm parameters. The importance of antioxidants in treating male subfertility continues to be questioned. Although there is enough evidence on high oxidative stress and low antioxidant capacity in the seminal plasma, there is little high-quality evidence in substantiating the use of antioxidants in the treatment of infertile men with abnormal semen parameters, including azoospermia [26]. Progesterone is prescribed in women treated with ovulation inducers or going through IVF procedure. The progesterone supplements are required to condense the uterine lining and prepare the body to support the embryo, so the embryo will successfully embed and grow. Compared to IVF/intracytoplasmic sperm injection methods, IUI is easy to execute, less expensive, and has particular advantages such as the minimal equipment required, easy to learn, being less invasive with a reduced psychological burden on the couple. Subsequently, IUI has a good couple adherence (low drop-out rate), a low risk for ovarian hyperstimulation syndrome, and a low rate of multiple pregnancy in natural cycles and clomiphene citrate or low-dose human menopausal gonadotrophins ovarian stimulation protocols [27].

\section{AUTHORS CONTRIBUTION}

All the authors have made substantial contribution to conception, design, data collection, analysis and interpretation of data. SSR: developing the concept and final approval, KK: contributed in manuscript overview. $\mathrm{AB}, \mathrm{AAV}, \mathrm{CJ}$ : data collection and manuscript writing.

\section{CONFLICTS OF INTEREST}

To the best of our knowledge, there are no conflicts of interest exists.

\section{REFERENCES}

1. Kumar D. Prevalence of Female Infertility and its Socio Economic Factors in Tribal Communities of Central India. Rural and Remote Health; 2007. Available from: http://www.rrh.org.au.

2. World Health Organization. In Fecundity, Infertility, and Childlessness in Developing Countries. DHS Comparative Reports No. 9. Calverton, Maryland, USA: ORC Macro and the World Health Organization; 2004.

3. Sciarra J. Infertility: An international health problem. Int J Gynaecol Obstet 1994:46:155-63.

4. Jumayev I, Harun-Or-Rashid M, Rustamov O, Zakirova N, Kasuya H, Sakamoto J, et al. Social correlates of female infertility in Uzbekistan. Nagoya J Med Sci 2012;74:273-83.

5. World Health Organization. Reproductive Health Indicators for Global Monitoring: Report of the Second Interagency Meeting, 2001. Geneva: World Health Organization; 2001. p. 23.

6. Boivin J, Bunting L, Collins JA, Nygren KG. International estimates of infertility prevalence and treatment-seeking: Potential need and demand for infertility medical care. Hum Reprod 2007;22:1506-12.

7. Jejeebhoy SJ. Infertility in India-levels, patterns and consequences: Priorities for social science research. J Fam Welf 1998;44:15-24.
8. Adamson PC, Krupp K, Freeman AH, Klausner JD, Reingold AL, Madhivanan $\mathrm{P}$, et al. Prevalence and correlates of primary infertility among young women in Mysore, India. Indian $\mathrm{J}$ Med Res 2011;134:440-6.

9. Daar A, Merali Z. Infertility and Social Suffering: The case of ART in Developing Countries. Geneva, Switzerland: World Health Organization; 2001. p. 16-21.

10. Campbell AJ, Irvine DS. Male infertility and intracytoplasmic sperm injection (ICSI). Br Med Bull 2000;56:616-29.

11. Laufer N, Yaffe H, Margalioth EJ, Livshin J, Ben-David M, Schenker JG, et al. Effect of bromocriptine treatment on male infertility associated with hyperprolactinemia. Arch Androl 1981;6:343-6.

12. Hirsh A. Male sub fertility. Br Med J 2003;327:669-72.

13. Hopps CV, Goldstein M, Schlegel PN. The diagnosis and treatment of the azoospermic patient in the age of intracytoplasmic sperm injection. Urol Clin North Am 2002;29:895-911.

14. Nestler JE, Stovall D, Akhter N, Iuorno MJ, Jakubowicz DJ. Strategies for the use of insulin-sensitizing drugs to treat infertility in women with polycystic ovary syndrome. Fertil Steril 2002;77:209-15.

15. Lavy G, Diamond MP, DeCherney AH. Ectopic pregnancy: Its relationship to tubal reconstructive surgery. Fertil Steril 1987;47:543-56.

16. Adamson GD, Baker VL. Subfertility: Causes, treatment and outcome. Best Pract Res Clin Obstet Gynaecol 2003;17:169-85.

17. Samal SK, Dhadwe K. Epidemiological study of male infertility. Indian Med Gaz 2012;145:174-80.

18. Khan MS, Ahmed Z, Hanif R, Zaman S, Ali I, Ur Rahman J, et al. Relationship between blood groups and male infertility. J Ayub Med Coll Abbottabad 2010:22:154-6.

19. Huda JD. Blood group and infertility relationship. Med J Babylon 2015;12:2-6.

20. Shanthakumari K, Reena WF, Anupama T. Prevalence of obesity among infertile women visited selected infertility clinic at Mangalore with a view to develop an informational pamphlet. IOSR J Nurs Health Sci 2014;3:7-10.

21. Chavarro JE, Toth TL, Wright DL, Meeker JD, Hauser R. Body mass index in relation to semen quality, sperm DNA integrity, and serum reproductive hormone levels among men attending an infertility clinic. Fertil Steril 2010;93:2222-31.

22. Olugbenga BA, Adebimpe W, Olarewaju S, Babatunde O, Oke O. Prevalence of infertility and acceptability of assisted reproductive technology among women attending gynecology clinics in tertiary institutions in Southwestern Nigeria. Obstet Gynecol 2014;4:1-7.

23. Keegan BR, Barton S, Sanchez X. Isolated teratozoospermia does not affect in vitro fertilization outcome and is not an indication for intracytoplasmic sperm injection. Fertil Steril 2007;88:1583-88.

24. Carlsen E, Giwercman A, Keiding N, Skakkebaek NE. Evidence for decreasing quality of semen during past 50 years. BMJ 1992;305:609-13.

25. Jørgensen N, Andersen AG, Eustache F, Irvine DS, Suominen J, Petersen $\mathrm{JH}$, et al. Regional differences in semen quality in Europe. Hum Reprod 2001;16:1012-9.

26. Magnusdottir EV, Thorsteinsson T, Thorsteinsdottir S, Heimisdottir M, Olafsdottir K. Persistent organochlorines, sedentary occupation, obesity and human male subfertility. Hum Reprod 2005;20:208-15.

27. Esteves SC, Agarwal A. Novel concepts in male infertility. Int Braz J Urol 2011;37:5-15 